http://jmscr.igmpublication.org/home/ ISSN (e)-2347-176x ISSN (p) 2455-0450

crossref DOI: https://dx.doi.org/10.18535/jmscr/v8i3.21

\title{
Effect of additive magnesium sulphate on spinal block characteristics in pre- eclampsia patients undergoing lower segment caesarean section
}

\author{
Authors
}

\section{Dr Sateesh Verma ${ }^{1 *}$, Dr Vijay Bahadur ${ }^{2}$, Dr Jyotsna Agarwal ${ }^{3}$, Dr Shobhna Jafa ${ }^{4}$, Dr Rajni Kapoor ${ }^{5}$}

${ }^{1}$ Associate Professor, Department of Anesthesiology, King George's Medical University, Lucknow

${ }^{2}$ Junior Resident, Department of Anesthesiology, King George's Medical University, Lucknow

${ }^{3,4,5}$ Professor, Department of Anesthesiology, King George's Medical University, Lucknow

*Corresponding Author

Dr Sateesh Verma

Department of Anesthesiology, King George's Medical University, Lucknow, India

\begin{abstract}
Background and Aims: Spinal anaesthesia is commonly used anaesthetic technique in preeclampsia patients. Adding additive in spinal anaesthesia improves block characteristics as well as prolongs post-operative analgesia. In this study we aimed to evaluate the effect of additive magnesium sulphate on sensory and motor block properties.

Methods: This prospective randomized study was conducted on 60 ASA II /III preeclampsia patients planned for caesarean section. Patients were randomly allocated to two groups and were given the following drugs intrathecally as per group allocation: Group $\mathrm{Mg}$ received $9 \mathrm{mg}$ of $0.5 \%$ bupivacaine heavy $(1.8 \mathrm{ml})+20$ microgram of fentanyl $50 \mu \mathrm{g} / \mathrm{ml}(0.4 \mathrm{ml})+50 \mathrm{mg}$ of $50 \% \mathrm{MgSO4}(0.1 \mathrm{ml})$. Group $\mathrm{NS}$ received $9 \mathrm{mg}$ of $0.5 \%$ bupivacaine heavy $(1.8 \mathrm{ml})+20$ microgram of fentanyl $50 \mu \mathrm{g} / \mathrm{ml}(0.4 \mathrm{ml})+0.1 \mathrm{ml}$ Normal Saline. Parameters monitored were sensory, motor block characteristics and postoperative analgesia.

Results: Time to regress sensory block to LI and postoperative analgesia was longerin group Mg. Time for complete motor recovery were significantly longer in group Mg as compared to group NS. Group Mg taken more time for onset of sensory and motor blockade.

Conclusion: Addition of magnesium sulphate at 50mg dose as adjuvants to intrathecal bupivacaine and fentanyl significantly prolongs period of the sensory and motor blockade. It also gives longer postoperative analgesia in preeclampsia patients undergoing caesarean section.

Keywords: Caesarean section, Spinal anesthesia, NMDA antagonists, Magnesium sulphate, Postoperative analgesia.
\end{abstract}

\section{Introduction}

Spinal anaesthesia is preferred anaesthetic technique in preeclampsia patients as it is safe and simple to perform in this patient group. It also provides excellent post-operative analgesia when some additive is used along with local anaesthetic agents $^{[1],[2],[3]}$

Neuraxial administration of magnesium as an analgesic adjuvant in the peri- operative setting are promising ${ }^{[4]}$. Magnesium has analgesic properties, primarily related to the regulation of calcium influx into cells ${ }^{[5]}$ and antagonism of $\mathrm{N}$ - methyl- $\mathrm{d}$ - aspartate (NMDA) receptors in the central nervous system ${ }^{[6],[7]}$. Intrathecal administration of magnesium sulphate has been shown to suppress nociceptive impulses in neuropathic pain and potentiates opioid antinociception in animal studies ${ }^{[8],[9]}$. It has been used in doses of $25-100 \mathrm{mg}$ along with local anaesthetic agent lidocaine, bupivacaine, levobupivacaine and ropivacaine with or without opioids $^{[10]}$. 
Magnesium sulphate is the drug of choice for prevention of seizures as part of comprehensive management of the disease. It is considered a safe drug to use in preeclampsia and eclampsia patient $^{[11]}$. In this study we added magnesium sulphate to evaluate its effect on sensory-motor block characteristics in preeclampsia patients undergoing caesarean section.

\section{Materials and Methods}

This prospective randomized controlled trial was carried out after obtaining ethics committee approval from our institution. We performed this study on 60 patients, aged 20-40 years who belonged to American society of anaesthesiologist (ASA) grade II or III. All patients were diagnosed cases of pre-eclampsia and were scheduled for caesarean section under spinal anaesthesia.

Pre- operative reassessment was done evening before surgery and patients were advised for 8 hours fasting before surgery. Exclusion criteria were coagulopathy, skin infection on back, placenta previa, severe foetal distress and patient on magnesium therapy. Written and informed consent was taken after explaining procedure and its consequences. Randomization in two groups was done by computer generated random number and group allocation was conducted by sealed envelopes. This study was single blinded as patients were unaware of what spinal anaesthesia drug they will be given.

After taking patient on operating table, intravenous access was obtained and pre- loading with $7.0 \mathrm{ml} / \mathrm{kg}$ of ringer lactate was done. Standard monitors such as pulse oximeter, electrocardiogram and non- invasive BP were used intraoperatively. Midline lumbar puncture was performed with 25-gauge Quincke spinal needle under standard aseptic precautions in sitting position at L3- L4 space. Patient were given spinal drugs according to group allocation:

Group Mg: $9 \mathrm{mg}$ of $0.5 \%$ bupivacaine heavy (1.8 $\mathrm{ml})+20$ microgram of fentanyl $50 \mu \mathrm{g} / \mathrm{ml}(0.4 \mathrm{ml})$ $+50 \mathrm{mg}$ of $50 \% \mathrm{MgSO}_{4}(0.1 \mathrm{ml})$.
Group NS: $9 \mathrm{mg}$ of $0.5 \%$ bupivacaine heavy $(1.8$ $\mathrm{ml})+20$ microgram of fentanyl $50 \mu \mathrm{g} / \mathrm{ml}(0.4 \mathrm{ml})$ + Normal Saline $(0.1 \mathrm{ml})$.

Patient was taken in supine position with left uterine displacement immediately after spinal anaesthesia. Supplemental oxygen via a face mask was given at a rate of 4-6 L/min. We evaluated following parameters during this study: Onset time to sensory block (dermatome T6), maximum height of sensory block achieved, time to regress sensory block to L1, time of onset of motor block, time to achieve complete motor block, time of complete motor recovery and time of first rescue analgesia required.

Onset time to sensory block was assessed as thetime interval between completion of injection of local anaesthetic solution to the loss of sensation at T6 dermatome. It was assessed by pinprick inthe midclavicular line bilaterally by a hypodermic needle every $2 \mathrm{~min}$ for $15 \mathrm{~min}$. Sensory block regression to L1 was assessed by pinprick at L1 after completion of surgery.

Motor block was assessed every two minutes for 20 minutes and then every 20 minutes after surgery till full motor recovery using modified Bromage scale $(0=$ able to move hip, knee \& feet, 1 = unable to move hip but able to move the knee \& feet, $2=$ unable to move hip, knee but able to move feet, 3 = unable to move the hip, knee and feet).Time of onset of motor blockade was assessed as the time interval between injection of local anaesthetic solution to the presence of grade1Bromagescale. Time of complete motor block was from completion of intrathecal injection to achieve Bromage score grade-3. Complete motor block recovery was considered as the time interval between completion of local anaesthetic injection to presence of grade-0 Bromage scale.

Post- operatively VAS scale was used to assess pain intensity and injection paracetamol $1.0 \mathrm{gm}$ administered intravenously as first line rescue analgesic once the VAS score was more than three. Duration of post- operative analgesia was noted from the time of injection of local anaesthetic to the first demand for rescue 
analgesic. Potential spinal drug side-effect such as itching, drowsiness, respiratory depression, nausea and vomiting were documented.

\section{Statistical Methods}

The results were obtained by comparisons between the group $\mathrm{Mg}$ and NS (Figure 1). Categorical data were summarized in proportions and percentages (\%) and quantitative data were summarized in mean \pm SD. Statistical comparison was carried out using the Chi-square or Independent Student's t-test. A value of $\mathrm{P}<0.05$ was considered statistically significant.

\section{Results}

The baseline characteristics of patients including age, weight andheight were comparable in both groups. The mean age of the patients in group $\mathrm{Mg}$ and group NS were $29.37 \pm 5.21$ years and $28.27 \pm 3.39$ years respectively. The mean height of patients was $158.40 \pm 20.54 \mathrm{~cm}$ and $154.57 \pm 6.70$ cmin group $\mathrm{Mg}$ and group NS respectively. The mean weight of patients in group $\mathrm{Mg}$ and group NS were $59.50 \pm 6.49$ kgand $57.7 \pm 5.87 \quad \mathrm{~kg}$ respectively (Table 1).

In both groups, most patient achieved T6 height of sensory block but in group $\mathrm{Mg}$ more patient achieved T4 level sensory block in comparison to group NS (36.7\% of group $\mathrm{Mg}$ and in $26.7 \%$ of group NS). Group Mg produced sensory block little later than group NS (8.40 min and $7.39 \mathrm{~min}$ respectively). Time to regress sensory block to L1 was longer in group $\mathrm{Mg}$. Time to $\mathrm{L} 1$ regression was 191.00 $\pm 31.74 \mathrm{~min}$ in group $\mathrm{Mg}$ and $163.83 \pm 16.73 \mathrm{~min}$ in group NS. This difference was found to be statistically significant (Table 2). Both onset time and time to achieve complete motor block was significantly prolonged in group $\mathrm{Mg}$. Complete motor block recovery time was longer in group $\mathrm{Mg}$ than group NS. So, addition of magnesium in spinal anaesthesia prolonged sensory and motor block significantly.

The time of first analgesic requirement was significantly longer in group $\mathrm{Mg}$. The time duration of first analgesic requirement was 222.33 min in group $\mathrm{Mg}$ and 208.50min in group NS (Table 2).

Incidence of common complication like nausea, pruritus and shivering were compared between groups but difference was not found to be statistically significant as shown in Table 3.We did not find any other significant complication in perioperative period (Table 3).

Table 1: Baseline characteristics of patients

\begin{tabular}{|l|c|c|c|c|c|}
\hline \multirow{2}{*}{ Parameters } & \multicolumn{2}{|c|}{ Group Mg } & \multicolumn{2}{c|}{ Group NS } & \multirow{2}{*}{ p-Value } \\
\cline { 2 - 5 } & Mean & $\mathbf{\pm S D}$ & Mean & $\mathbf{\pm S D}$ & \\
\hline Age (years) & 29.37 & 5.21 & 28.27 & 3.39 & 0.337 \\
\hline Weight $(\mathrm{kg})$ & 59.50 & 6.49 & 57.7 & 5.87 & 0.253 \\
\hline Height $(\mathrm{cm})$ & 158.40 & 20.54 & 154.57 & 6.70 & 0.335 \\
\hline
\end{tabular}

$\mathrm{SD}=$ Standard deviation, ${ }^{1}=$ Independent $\mathrm{t}$-test

Table 2: Comparison of Sensory and Motor Block Characteristics

\begin{tabular}{|c|c|c|c|c|c|}
\hline \multirow[t]{2}{*}{ Parameters } & \multicolumn{2}{|c|}{ Group Mg } & \multicolumn{2}{|c|}{ Group NS } & \multirow[t]{2}{*}{${ }^{1} \mathrm{p}$-Value } \\
\hline & $\begin{array}{c}\text { Mean } \\
\text { m(min) }\end{array}$ & \pm SD & $\begin{array}{l}\text { Mean } \\
(\text { min })\end{array}$ & $\pm \mathrm{SD}$ & \\
\hline $\begin{array}{l}\text { Highest dermatome level of sensory block } \\
\text { achieved T4/T6 }\end{array}$ & \multicolumn{2}{|c|}{$11(36.7 \%) / 19(63.3 \%)$} & \multicolumn{2}{|c|}{$8(26.7 \%) / 22(73.3 \%)$} & 0.168 \\
\hline Onset time of sensory block (T6 level) & 8.40 & 2.77 & 7.39 & 2.88 & 0.181 \\
\hline Time to regression of sensory block to L1 & 191.00 & 31.74 & 163.83 & 16.73 & $<0.001^{*}$ \\
\hline Onset time of motor block & 5.50 & 2.24 & 4.50 & 1.89 & 0.067 \\
\hline Time of completes motor block & 9.80 & 2.83 & 7.76 & 2.81 & $0.03^{*}$ \\
\hline Time taken for complete motor recovery & 194.33 & 16.12 & 181.67 & 24.79 & $0.022^{*}$ \\
\hline Duration of postoperative analgesia & 222.33 & 17.75 & 208.50 & 23.75 & $<0.013^{*}$ \\
\hline
\end{tabular}

$\mathrm{SD}=$ Standard deviation, ${ }^{1}=$ Independent $\mathrm{t}$-test, ${ }^{*}=$ Significant $(\mathrm{p}<0.05)$ 
Table 3: Comparison of Adverse Effects

\begin{tabular}{|l|c|c|c|}
\hline Parameters & Group Mg & Group NS & ${ }^{\mathrm{l}} \mathrm{p}$-Value \\
\hline Nausea & $6(20 \%)$ & $5(16.67 \%)$ & 0.131 \\
\hline Pruritus & $2(6.67 \%)$ & $3(10.0 \%)$ & 0.456 \\
\hline Shivering & 0 & 0 & - \\
\hline
\end{tabular}

${ }^{1}=$ Independent $\mathrm{t}$-test

Figure 1: Consort flow diagram

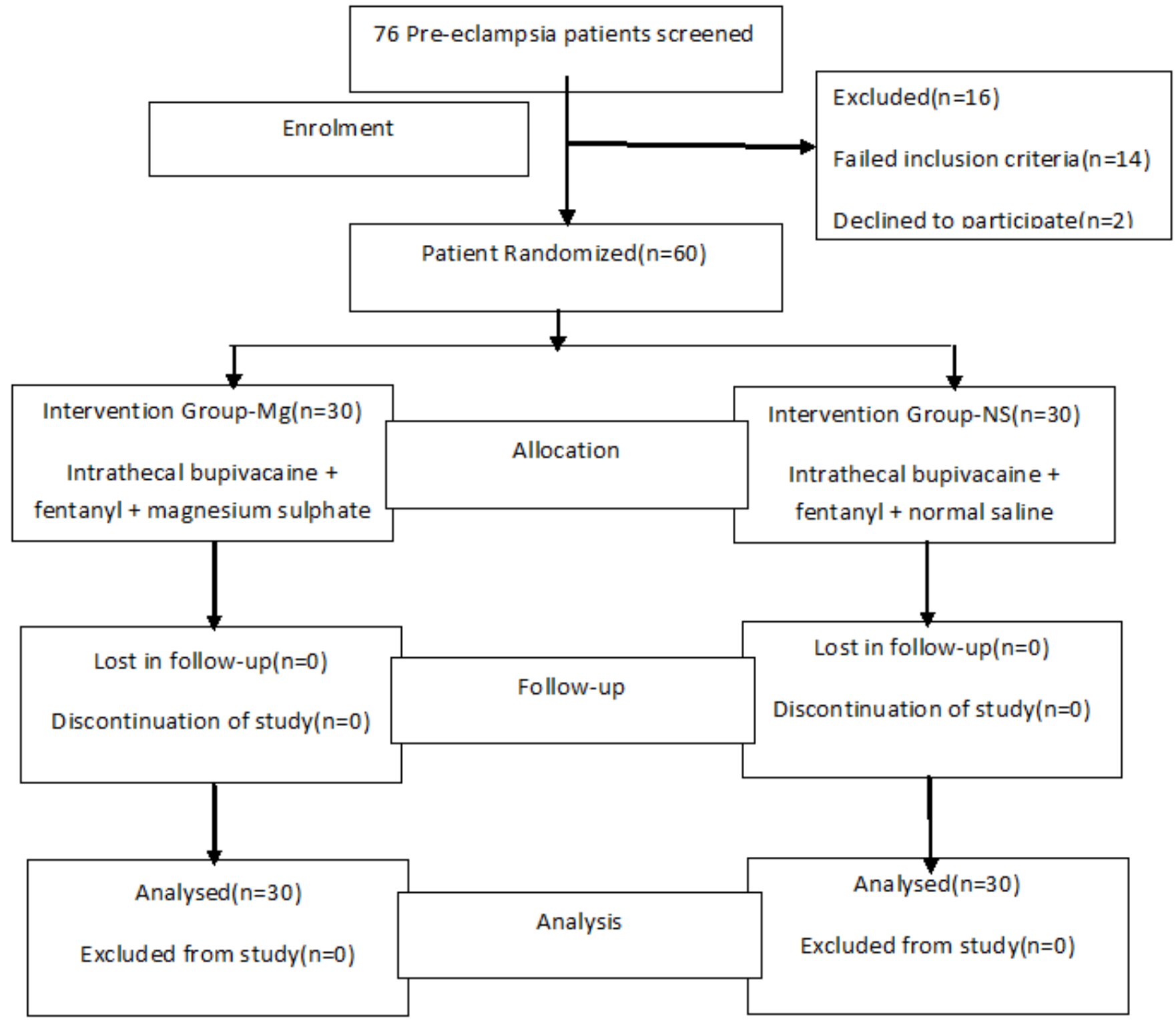

\section{Discussion}

Additive in spinal anaesthesia is a common practice in obstetric patient to improve quality of anaesthesia as well as prolongs its durations. Prolonged analgesia in post-operative periods may be useful as it reduced post-operative stress as well as analgesic requirement. Decreased stress response in preeclampsia patient is desirable as these patients are already physiologically compromised. We conducted the study to evaluate the effects and safety of adjuvant magnesium sulphate in spinal anaesthesia.

In present study both groups were comparable for age, weight and height as we found no significant difference between them. In our study duration of postoperative analgesia and time taken for complete motor recovery was longer when magnesium was added in spinal anaesthesia drugs. 
But onset of sensory and motor block was delayed in magnesium group than normal saline group.

M Ozalevli (2005) conducted study on patients undergoing lower extremity surgery with addition of magnesium sulphate (50mg) to spinal anaesthesia. They observed that adjuvant magnesium significantly delayed the onset of both sensory and motor blockade but prolonged the period of anaesthesia without additional side- effects. Their findings were like ours, however difference was that their patients undergone lower limb surgery and our caesarean section $^{[12]}$.

Malleeswaran et al. (2010) observed that in mild preeclampsia women undergoing caesarean section, the addition of magnesium sulphate 50 $\mathrm{mg}$ to the intrathecal combination of bupivacaine and fentanyl prolongs sensory block regression to T12 $(\mathrm{P}<0.001)$ and total duration of motor block were significantly longer in the magnesium group $(\mathrm{P}<0.001)$. Both these finding was similar to our observations $^{[13]}$.

Our study results correlate with other done by MP Nath et al. (2012). The found that addition of 100 $\mathrm{mg}$ intrathecal magnesium led to prolonged duration of analgesia significantly without increasing the incidence of side-effects. Also, there was a significant delay in the onset of both sensory and motor blockade. Here difference with our study was that they used $100 \mathrm{mg}$ magnesium sulphate and their patients underwent total abdominal hysterectomy ${ }^{[14]}$.

Similarly, Kathuria B et al. (2014) had given magnesium sulphate $50 \mathrm{mg}$ and $75 \mathrm{mg}$ along with local anaesthetic intrathecally for orthopaedic lower limb surgery under subarachnoid block. The found that time of maximum sensory block, time of onset of motor block, duration of sensory block, duration of motor block and time of analgesia request were prolonged in magnesium group than control group ${ }^{[15]}$.

So, these previously conducted study found that adding magnesium sulphate intrathecally prolonged sensory, motor block and prolonged postoperative analgesia without increasing the incidence of drug related side-effects. Prolonged sensory block and delayed postoperative analgesia requirement indicate that magnesium sulphate may be useful as an adjuvant in spinal anaesthesia. Limitations of our study were small sample size, single center study and multiple drugs used in intrathecal injection. Result of study could not be applied to general population due to narrow population group.

\section{Conclusions}

In pre-eclampsia patients undergoing caesarean surgery, the addition of magnesium sulphate 50 $\mathrm{mg}$ to the intrathecal combination of bupivacaine and fentanyl prolongs the duration of postoperative analgesia without additional side effects.

\section{Acknowledgments: None}

\section{References}

1. Sia AT, Fun WL, Tan TU. The ongoing challenges of regional and general anaesthesia in obstetrics. Best Pract Res Clin ObstetGynaecol.2010;24:303-12.

2. Gogarten W. Spinal anaesthesia for obstetrics. Best Pract Res Clin Anaesthesiol. 2003;17:377-92.

3. Burns SM, Cowan CM. Spinal anaesthesia for caesarean section: current clinical practice. Hospital medicine. 2000;61:8558.

4. Albrecht E, Kirkham KR, Liu SS, Brull R. The analgesic efficacy and safety of neuraxial magnesium sulphate: a quantitative review. Anaesthesia. 2013 Feb; 68(2):190-202

5. Iseri LT, French JH. Magnesium: nature's physiologic calcium blocker. American Heart Journal1984; 108: 188- 93.

6. Woolf CJ, Thompson SW. The induction and maintenance of central sensitization is dependent on $\mathrm{N}$ - methyl- D- aspartic acid receptor activation; implications for the treatment of post- injury pain 
hypersensitivity states. Pain 1991; 44: 293-9.

7. Feria M, Abad F, Sanchez A, Abreu P. Magnesium sulphate injected subcutaneously suppresses autotomy in peripherally deafferented rats. Pain1993; 53: 287-93.

8. Xiao WH, Bennett GJ. Magnesium suppresses neuropathic pain responses in rats via a spinal site of action. Brain Res. 1994;666:168-72.

9. Kroin JS, McCarthy RJ, Von Roenn N, Schwab B, Tuman KJ, Ivankovich AD. Magnesium sulfate potentiates morphine antinociception at the spinal level. AnesthAnalg. 2000;90:913-7.

10. Seyhan TÖ, Bezen O, Sungur MO, Kalelioğlu İ, Karadeniz M, Koltka K. Magnesium therapy in pre-eclampsia prolongs analgesia following spinal anaesthesia with fentanyl and bupivacaine: an observational study. Balkan Med J.2014;2014:143-8.

11. Smith JM, Lowe RF, Fullerton J, Currie SM, Harris L, Felker-Kantor E. An integrative review of the side effects related to the use of magnesium sulfate for pre-eclampsia and eclampsia management. BMC pregnancy and childbirth. 2013 Dec;13(1):34.

12. Özalevli M, Cetin TO, Unlugenc H, Guler $\mathrm{T}$, Isik $\mathrm{G}$. The effect of adding intrathecal magnesium sulphate to bupivacainefentanyl spinal anaesthesia. Acta Anaesthesiol Scand.2005;49:1514-9.

13. Malleeswaran S, Panda N, Mathew P, Bagga R. A randomised study of magnesium sulphate as an adjuvant to intrathecal bupivacaine in patients with mild preeclampsia undergoing caesarean section. Int J ObstetAnesth.2010;19:161-6.
14. Nath MP, Garg R, Talukdar T, Choudhary D, Chakrabarty A. To evaluate the efficacy of intrathecal magnesium sulphate for hysterectomy under subarachnoid block with bupivacaine and fentanyl: A prospective randomized double blind clinical trial. Saudi journal of anaesthesia. 2012 Jul;6(3):254.

15. Kathuria B, Luthra N, Gupta A, Grewal A, Sood D. Comparative efficacy of two different dosages of intrathecal magnesium sulphate supplementation in subarachnoid block. Journal of clinical and diagnostic research: JCDR. 2014 Jun;8(6):GC01. 